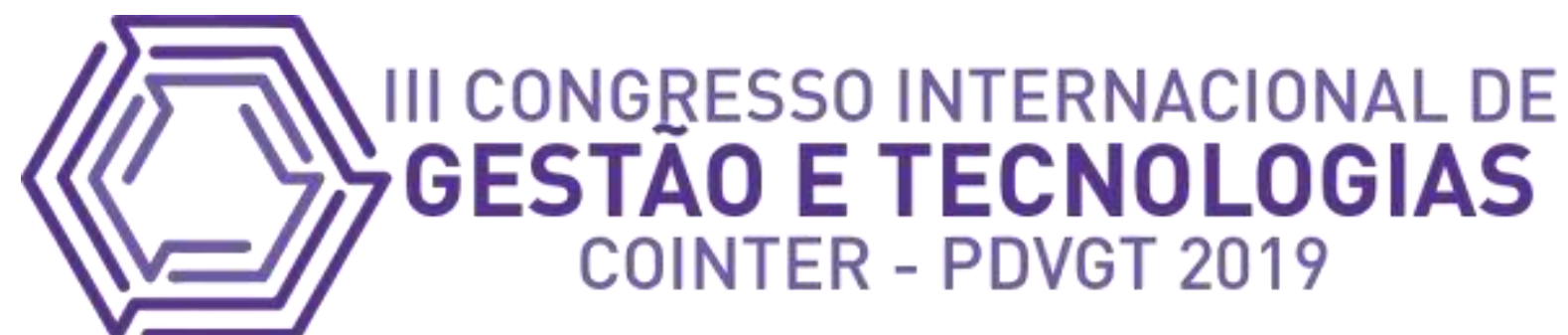

\title{
PRÁTICAS SUSTENTÁVEIS DE DESCARTE DE LIXO ENTRE OS ESTUDANTES DO IFPE - CAMPUS RECIFE
}

\section{PRÁCTICAS SUSTENTABLES DE ELIMINACIÓN DE BASURA ENTRE ESTUDIANTES DE IFPE - CAMPUS RECIFE}

\section{SUSTAINABLE WASTE DISPOSAL PRACTICES AMONG STUDENTS OF THE CAMPUS RECIFE - IFPE}

\author{
Apresentação: Comunicação Oral \\ Aline Alves Guimarães ${ }^{1}$; Simone de Paula Silva²; Derek Luiz Alves dos Santos ${ }^{3}$; Erick Viana \\ da Silva ${ }^{4}$
}

\section{DOI: https://doi.org/10.31692/2358-9728.VICOINTERPDVG.2019.0051}

\section{Resumo}

O presente artigo tem como finalidade debater a respeito dos resultados de uma pesquisa feita com os estudantes do Instituto Federal de Ciência e Tecnologia de Pernambuco campus Recife a respeito das formas sustentáveis de descarte de lixo. A sustentabilidade é tudo aquilo feito a favor de um ecossistema para que ele continue em equilíbrio e não só conservado, mas também próspero e capaz de evoluir. Além disso, as várias mudanças históricas que o comportamento do ser humano sofreu fizeram com que a produção de resíduos aumentasse e, consequentemente, o lixo passasse a se tornar um grande problema ambiental. Dessa maneira, os dados obtidos foram analisados dentro desse contexto e debatidos a respeito dos impactos ambientais que as formas errôneas de descartar o lixo causam. Nesse trabalho foram abordadas as temáticas da reciclagem, da separação de resíduos, do lixo eletrônico e do uso de sacolas plásticas. A pesquisa foi feita através de um questionário on-line com cinco questões objetivas e foram entrevistados 126 alunos dos cursos técnicos integrados de segurança do trabalho, eletrônica, eletrotécnica, edificações, química e saneamento. Após o agrupamento dos resultados obtidos, organizou-se os dados em um software de edição de planilhas para transformá-los em porcentagem. Foi possível observar que ainda existe uma tendência à adoção de práticas não-sustentáveis de descarte pela maioria dos estudantes. Portanto, conhece-se a importância desse tema atualmente uma vez que nos leva a refletir a respeito da

\footnotetext{
${ }^{1}$ Estudante do Curso Técnico Integrado de Segurança do Trabalho, Instituto Federal de Educação, Ciência e Tecnologia de Pernambuco, alinealvesguimar@gmail.com

2 Mestra em Gestão Ambiental, Instituto Federal de Educação, Ciência e Tecnologia de Pernambuco, simone.depaula@recife.ifpe.edu.br

${ }^{3}$ Mestrando em Gestão do Desenvolvimento Local Sustentável (Universidade de Pernambuco), Especialista em Administração Pública, Instituto Federal de Educação, Ciência e Tecnologia de Pernambuco, derek_rec@hotmail.com

${ }^{4}$ Mestre em Administração de Empresas, Instituto Federal de Educação, Ciência e Tecnologia de Pernambuco, erick.viana@recife.ifpe.edu.br
} 
interferência humana na natureza e como os jovens podem reverter essa situação engajando-se nas causas ambientais.

Palavras-chave: Sustentabilidade, resíduos, coleta seletiva, reciclagem.

\title{
Resumen
}

El propósito de este artículo es discutir los resultados de uma encuesta realizada com estudiantes del Instituto Federal de Ciencia y Tecnología del campus Recife em Pernambuco sobre formas sostenibles de eliminación de desechos. La sostenibilidad es todo lo que se hace a favor de un ecosistema para que se mantenga en equilibrio y no solo conservado, pero también próspero y capaz de evolucionar. Además, los diversos cambios históricos que ha sufrido el comportamiento humano han provocado un aumento de la producción de desechos $\mathrm{y}$, como resultado, los desechos se han convertido en um grande problema ambiental. Por lo tanto, los datos obtenidos se analizaron dentro de este contexto y se debatieron sobre los impactos ambientales que causan las formas incorrectas de eliminación de desechos. Este trabajo abordó los temas de reciclaje, separación de desechos, desechos electrónicos y el uso de bolsas de plástico. La encuesta se realizó a través de un cuestionario en línea con cinco preguntas objetivas y se entrevistó a 126 estudiantes de los cursos técnicos integrados de seguridad del trabaho, electrónica, electrotécnica, edificaciones, química y saneamiento. Después de agrupar los resultados obtenidos, los datos se organizaron en un software de edición de hojas de cálculo para transformarlos en un porcentaje. Se observó que todavía existe una tendencia a la adopción de prácticas de eliminación no sostenibles por parte de la mayoría de los estudiantes. Por lo tanto, se conoce la importancia de este tema, ya que nos lleva a reflexionar sobre la interferencia humana en la naturaleza y cómo los jóvenes pueden revertir esta situación al involucrarse en causas ambientales.

Palabras Clave: Sostenibilidad, residuos, recogida selectiva, reciclaje.

\begin{abstract}
The present article aims to discuss the results of a survey done with campus Recife Pernambuco Federal Education, Science and Technology Institute students about the sustainable ways of waste disposal. Sustainability is all that is done for an ecosystem so that it remains in balance and not only conserved, but also prosperous and able to evolve. Besides that, the various historical changes that human behavior has undergone have increased the production of waste and, consequently, it has become a major environmental problem .Thus, the data obtained was analyzed within this context and the environmental impacts that the wrong ways of disposing of trash cause were debated. In this work, the themes of recycling, waste separation, electronic waste and the use of plastic bags were approached. The survey was conducted through an online questionnaire with five objective questions and 126 students from the integrated technical courses of occupational safety, electronics, electrotechnics, edifications, chemistry and sanitation were interviewed. After grouping the obtained results, the data was organized in a plan editing software to transform it into a percentage. It was observed that there is still a tendency for the adoption of unsustainable disposal practices by most students. Therefore, it is known the importance of this theme today, as it leads us to reflect on human interference in nature and how young people can reverse this situation by engaging in environmental causes.
\end{abstract}

Keywords: Sustainability, waste, selective collection, recycling. 


\section{Introdução}

Após a Primeira Revolução Industrial, foi possível observar um considerável aumento da população e um estímulo ao consumo presente nas sociedades capitalistas. Atrelado a isso, também houve outro grande crescimento populacional e uma consequente maior produção de lixo depois da Segunda Guerra Mundial (1939 a 1945). Esse crescimento só foi possível pela modernização e expansão da economia capitalista, mas também pelo crescimento demográfico e pela expansão de empresas transnacionais que passaram a difundir em escala global os mais diversos produtos de consumo pessoal e coletivo. (HOCH, 2016). A partir desse período, o mundo passou a sofrer transformações comerciais, tecnológicas e sociais, havendo, então, dispersão de várias empresas que, ora lançam, constantemente, diversas novidades no mercado. Entretanto, pouco se falou e se fala a respeito do lixo produzido, e de seu correto destino.

Atualmente, conseguimos ver a um aumento da conscientização da população a respeito do meio ambiente. A sociedade está passando por um momento de transição na educação ambiental, e passa a firmar a tomada de iniciativas que visam ao futuro. (WIESEL, 2010). Não obstante, segundo dados do Ministério do Meio Ambiente, o brasileiro claramente evoluiu a sua consciência ambiental durante o período de 1992 a 2012. Dessa forma, o que se estima é que os números continuem a subir, isso, a partir do engajamento de jovens que nasceram após a década de 1990 (geração Z), nas questões ambientais.

É importante lembrar que cada ser humano possui o dever de agir em prol da manutenção da vida no planeta Terra. E assim, fazer com que essa ideia atinja a uma escala maior, não será fácil, porém, entender que nossas atuais atitudes definirão o futuro, é essencial.

Segundo a Comissão da Carta da Terra (1992), temos que escolher entre formar uma aliança global para cuidar do planeta ou arriscar a destruição da vida existente. Por isso, são necessárias mudanças essenciais dos nossos valores, instituições e modos de vida. Sendo assim, o objetivo geral é analisar o engajamento dos estudantes nas questões ambientais, isso, a partir da aplicação de um questionário.

\section{Fundamentação Teórica}


Antqueves, Bosa e Dubiaski-Silva (2015) afirmam que a definição de lixo não é fácil de ser contextualizada. A palavra é derivada do termo lix, que significa "cinza", já que antigamente os resíduos de cozinha eram formados basicamente por restos de lenha carbonizada. Então, assim como os outros animais, o ser humano também passa pelo processo de produção de resíduos. Porém, as mudanças históricas no comportamento humano fizeram do lixo um grande problema ambiental sem solução definitiva. (CARDOSO, F.; CARDOSO, J., 2016)

Segundo Alencar (2005), a reciclagem consiste em uma série de atividades pelas quais o lixo seja processado e transformado em matéria-prima. Portanto, é o aproveitamento de resíduos para fabricar novos produtos. Essa prática é vista como uma solução para a redução da quantidade de lixo no mundo.

Ainda de acordo com Alencar (2005), as residências domiciliares são capazes de produzir diferentes tipos de resíduos, sejam eles inofensivos ou perigosos à saúde humana. A partir desse fato, surge a necessidade da coleta seletiva, uma vez que previne possíveis acidentes no meio em que indivíduos da área de reciclagem trabalham.

O lixo eletrônico é todo tipo de resíduo proveniente de aparelhos eletrônicos, celulares, computadores, entre outros. De acordo com Celinski et al. (2011), quando esse tipo de resíduo é despejado diretamente no lixo comum, as substâncias químicas presentes nos aparelhos contaminam o solo e os lençóis freáticos.

Segundo Calvão et al. (2009), os aparelhos eletrônicos possuem um custo de compra relativamente baixo e um custo de reparo caro. Dessa forma, há a preferência por adquirir uma nova máquina ao invés de consertar a antiga. Consequentemente, causa uma maior produção de e-lixo.

De acordo com Piatti e Rodrigues (2005), a palavra plástico vem do grego plástikos. Em função de seu uso tão difundido, grande parte do lixo que produzimos diariamente é composto deste material. Ele se decompõe muito lentamente e vem acarretando sérios problemas ambientais. Ainda conforme Piatti e Rodrigues (2005), têm sido necessários aterros sanitários cada vez maiores para acolher o impressionante volume de lixo que produzimos diariamente.

\section{Metodologia}


O trabalho em tela é uma pesquisa de natureza aplicada com abordagem quantitativa. O enfoque foi descritivo, com a utilização de instrumento técnico de pesquisa do tipo formulário, com 5 questões objetivas sobre a forma como o respondente trata o lixo produzido em sua residência. Além disso, as questões tiveram como base os principais tópicos acerca do assunto abordado: reciclagem, formas de descarte e produção de lixo. Quanto ao procedimento de pesquisa, trata-se de um estudo de caso. Os sujeitos foram 126 alunos dos cursos Técnicos Integrados de Segurança do Trabalho, Eletrônica, Eletrotécnica, Edificações, Saneamento e Química do IFPE (Instituto Federal de Pernambuco) - Campus Recife. Após o agrupamento dos resultados obtidos com o questionário, utilizou-se um software de edição de planilha para transformar os dados em porcentagem.

Quadro 1-Questionário fechado

\section{Questões contidas na pesquisa realizada em 2019:}

1- Qual é o seu curso?

2- Você recicla e/ou dá outra finalidade ao lixo produzido em sua casa?

( ) Sim ( ) Não ( ) Às vezes

3- Você faz separação do lixo em sua casa?

( ) Sim ( ) Não ( ) Às vezes

4- Em relação ao lixo eletrônico, qual é a forma de descarte utilizada em sua casa?

( ) Descarto da mesma forma que o lixo comum ( ) Levo aos locais apropriados para o descarte desse tipo de resíduo ( ) Outros

5- Quando você vai às compras, você opta levar os produtos em sacolas plásticas ou sacolas reutilizáveis?

( ) Sacolas plásticas ( ) Sacolas reutilizáveis ( ) Depende

Fonte: Autoria Própria, 2019

\section{Resultados e Discussões}

- A separação e a Reciclagem dos Resíduos Domiciliares: 


\section{Você recicla e/ou dá outra finalidade ao lixo produzido em sua casa?}

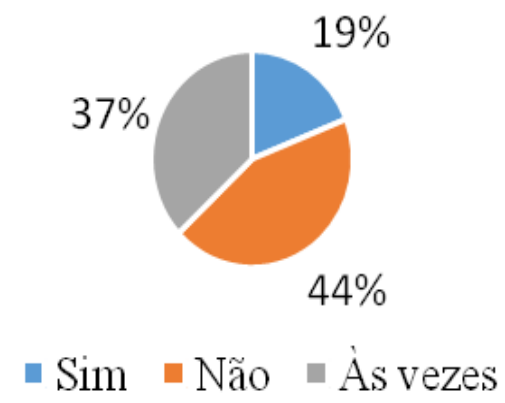

Fonte: Autoria Própria, 2019

De acordo com a pesquisa realizada, foi possível visualizar uma diferença notória quando os alunos foram questionados a respeito da reciclagem de resíduos domiciliares. Apenas 19\% dos participantes afirmaram praticar tal ação, 37\% admitiram realizar às vezes, ou seja, com pouca frequência. Já os $44 \%$ restante afirmam não praticar tal ação, o que gera a reflexão da necessidade de reciclar tendo em vista sua grande importância e consequência.

A maioria dos produtos utilizados pela humanidade não é totalmente consumida, restando, assim, uma parcela significativa de resíduos. Esses "restos" poderão ter três destinos: são lançados diretamente na natureza, são encaminhados para aterros sanitários ou passam por um reprocessamento e estes produtos, uma vez descartados, voltam ao mercado. Esse último destino é chamado de reciclagem. (SOUZA, 2011)

A reciclagem permite que os resíduos sólidos retornem para o processo produtivo e, consequentemente, diminui o volume de lixo acumulado em aterros e lixões. Segundo o Ministério do Meio Ambiente, cerca de 30\% de todo o lixo é composto de materiais recicláveis como papel, vidro, plástico e latas. Todos esses resíduos têm valor de mercado, pois são reaproveitados como matéria-prima no processo de fabricação de novos produtos.

"A geração de resíduos sólidos urbanos (RSU) foi de 78,4 milhões de toneladas em 2017, aumento de cerca de 1\% em relação a 2016". (ABRELPE, 2017). Dessa forma, a reciclagem poderia proporcionar uma redução no número de resíduos caso fosse mais praticada. Infelizmente, o Brasil não possui tantos programas de incentivo para dar outra finalidade ao lixo. 


\section{Você faz a separação do lixo em sua casa?}

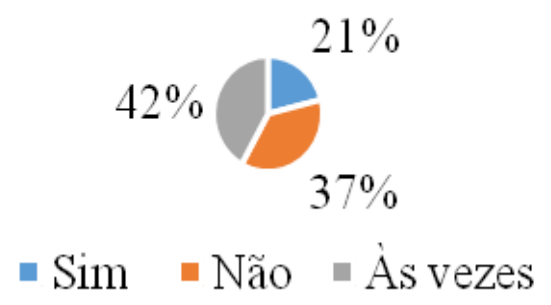

Fonte: Autoria Própria, 2019.

Infelizmente, a coleta seletiva ainda não se tornou parte do cotidiano de boa parte dos brasileiros, e podemos visualizar isso claramente no Gráfico 2. De acordo com os dados obtidos na entrevista, é possível observar que apenas uma pequena minoria (21\%) dos estudantes praticam a coleta seletiva. Já $42 \%$ dos entrevistados afirmaram que praticam ocasionalmente e $37 \%$ não separam o lixo.

A coleta seletiva tem como objetivo a separação dos materiais que podem ser recuperados, com um tratamento diferente para cada material. Por isso, vale salientar também a necessidade da separação do lixo no meio domiciliar. Essa prática simples pode proporcionar mais facilidade aos trabalhadores da área de reciclagem, uma vez que eles poderão manusear os resíduos sem correrem o risco de se machucarem.

A coleta de lixo é um método mais eficaz de triagem e reaproveitamento dos resíduos domiciliares, comerciais e industriais. Seu processo logístico é racional desde sua origem até sua disposição para reutilização, bem como para depósito final em aterros, incineradores, lixões, valas sépticas, entre outros. (FROTA et al., 2015)

No meio urbano, a coleta seletiva é um instrumento de incentivo à redução, à reutilização e à separação do material para a reciclagem, buscando uma mudança de comportamento, principalmente em relação aos desperdícios inerentes à sociedade de consumo. (FROTA et al., 2015)

De acordo com o Ministério do Meio Ambiente, as formas mais comuns de coleta seletiva existem no Brasil atualmente são a coleta por Pontos de Entrega Voluntária (PEVs) e coleta porta-a-porta. Os PEVs consistem em lugares situados de forma estratégica próximos de um conjunto de residências ou instituições para entrega dos resíduos já separados e posterior coleta pelo poder público. Já a coleta porta-a-porta ocorre através de um caminhão 
ou outro veículo que passa em frente às residências e comércios recolhendo os resíduos separados pela população.

- O Descarte Incorreto do Lixo Eletrônico e Seus Impactos:

Gráfico 3 -Lixo Eletrônico

Em relação ao lixo eletrônico, qual é a forma de descarte utilizada em sua casa?

$13 \%$

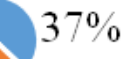

$50 \%$

- Descarto da mesma forma que o lixo comum

- Levo à locais apropriados e especializados para o descarte

- Outros

Fonte: Autoria Própria, 2019.

Na questão do lixo eletrônico, é possível visualizar que metade dos sujeitos praticam o descarte de maneira correta, levando à locais que possuem suporte para o descarte do tipo de material abordado, o lixo eletrônico. Os outros 50\% afirmaram realizar tal ação de maneira errônea ou não citada. Sendo 37\%, os entrevistados que admitiram descartar o material da mesma forma que o lixo comum, ou seja, de maneira incorreta, e os $13 \%$ restante dos participantes afirmaram realizar a ação através de outros meios não citados.

Segundo o relatório internacional do Global E-Waste Monitor 2017, o Brasil gerou, no ano de 2016, um total de 1,5 milhão de toneladas de lixo eletrônico que não teve destinação 
adequada. Dessa forma, pode-se observar que a população brasileira ainda não tornou o descarte correto do e-lixo algo cotidiano.

De acordo com Santos e Souza (2010), o acelerado avanço tecnológico está causando a procura crescente por equipamentos mais modernos; produzindo, dessa forma, um aumento na produção do lixo eletrônico. Essa alta geração de produtos visa ao atendimento da necessidade de substituição dos aparelhos em uso, fenômeno que está ocorrendo em intervalos de tempo cada vez mais curtos, uma vez que os artigos eletrônicos passam a ser considerados obsoletos rapidamente. Assim, a redução da durabilidade não se resumiria somente duração menor de um produto, mas também a perda de sua utilidade depois de determinado período de tempo, o que contribui para o lucro empresarial e traz prejuízos ao meio ambiente. $(\mathrm{HOCH}$, 2016)

Sabe-se que o e-lixo pode vir a causar grandes impactos ao meio ambiente e à saúde humana quando é descartado incorretamente. Vários metais pesados compõem aparelhos eletrônicos do nosso cotidiano e, quando expostos diretamente ao solo, contaminam a área atingida.

Um exemplo de metal utilizado é o chumbo, componente de computadores e aparelhos celulares. O sistema nervoso, a medula óssea e os rins são considerados órgãos críticos para o chumbo, que interfere nos processos genéticos ou cromossômicos e produz alterações na estabilidade da cromatina, agindo como promotor do câncer. Por isso está ligado ao câncer de pele e de pulmão. Além disso, a contaminação do solo pelo chumbo é um processo acumulativo praticamente irreversível. (LOBO, 2011)

Outro exemplo que podemos encontrar é o cádmio, elemento que possui de 10 a 30 anos de vida biológica e é de lenta excreção pelo organismo humano. O órgão alvo afetado pela exposição prolongada ao elemento é o rim. Assim, os efeitos tóxicos do cádmio causam distúrbios gastrointestinais e hepáticos, além de promover a excreção do cálcio e a depleção de zinco. A principal forma de contaminação é por inalação, assim, inalar doses elevadas desse elemento produz intoxicação aguda, caracterizada por edema pulmonar e pneumonite. (LOBO, 2011)

Além dos já citados, também existe o mercúrio, metal pesado que se encontra em celulares, monitores, televisores e computadores. A progressiva utilização do mercúrio para fins industriais e o emprego de compostos com esse elemento durante grandes períodos de tempo na agricultura resultaram no aumento significativo da contaminação ambiental, 
especialmente da água e dos alimentos. Uma das razões que contribuem para o agravamento dessa contaminação é o Ciclo do Mercúrio no meio ambiente. A biotransformação por bactérias do mercúrio inorgânico a metilmercúrio é o processo responsável pelos elevados níveis do metal no ambiente. Assim, a exposição a elevadas concentrações desse metal pode provocar edema pulmonar, dispneia, pneumomediastino, enfisema, cianose e, em alguns casos, até a morte. (LOBO, 2011)

Ainda nesse contexto, destacam-se as atividades dos coletores de recicláveis, que encontram o e-lixo durante o trabalho e fazem a separação manual dos seus componentes, geralmente sem o conhecimento necessário sobre os riscos a que estão sendo expostos e os impactos ambientais que podem vir a ocorrer. (CELINSKI, et al., 2013)

De acordo com Calvão et al., a alternativa mais prática para o processo de redução desse problema é reverter velhos hábitos, como, por exemplo, o de jogar baterias de celulares no lixo comum ou o de comprar um novo aparelho eletrônico quando já se possui um que funciona perfeitamente.

- O uso exagerado de Plástico:

Gráfico 4 - Sacolas Plásticas

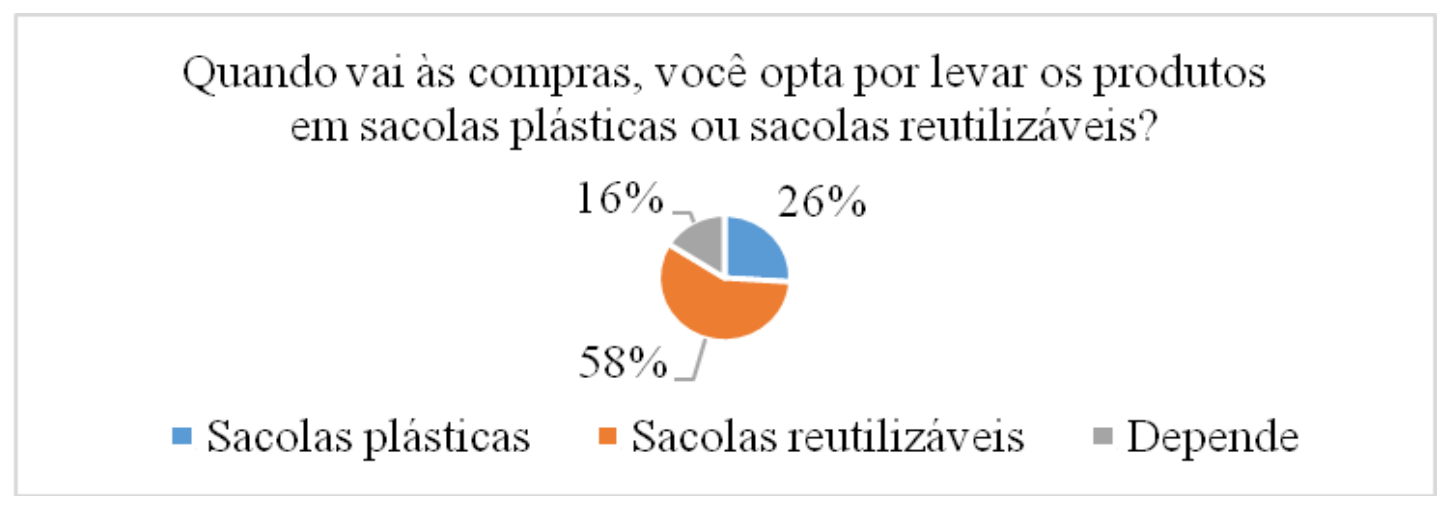

Fonte: Autoria Própria, 2019

A partir do Gráfico 4, é possível visualizar não só os resultados obtidos, mas principalmente a diferença considerável da conscientização dos participantes. Mais da metade dos entrevistados (58\%) optam pelo uso de sacolas reutilizáveis tendo em vista suas consequências para o meio ambiente. Uma porcentagem de $26 \%$ ainda utiliza as sacolas plásticas durante as compras. 
De acordo com o relatório "Valuing Plastic", divulgado pela Organização das Nações Unidas no ano de 2014, o custo financeiro dos prejuízos ambientais relacionados ao plástico ultrapassa US\$ 75 bilhões anuais. (ONU, 2014 apud INSTITUTO AKATU, 2014). Dessa forma, as simples embalagens plásticas que fazemos uso todos os dias causam um impacto no meio ambiente enorme a longo prazo, trazendo prejuízos à fauna e à flora.

Segundo Landim et al., o uso do plástico tem como vantagens o baixo custo, baixo peso, resistência mecânica e flexibilidade. Em contrapartida, a grande desvantagem observada é que, em sua maioria, o plástico não é biodegradável e leva mais de 100 anos para serem completamente degradados pela natureza. Sua produção emite gases poluentes e é completamente dependente do petróleo, que é um recurso natural não renovável.

De acordo com Faria e Pacheco (2011), as embalagens plásticas, como filmes de invólucros de alimentos, garrafas de bebidas, recipientes de produtos lácteos, como manteiga e iogurtes, sacos, copos e frascos de produtos de limpeza e higiene têm ciclos de vida útil curtos e são rapidamente descartados pelo consumidor e encaminhados para o destino final, transformando-se em resíduos.

Além disso, causa uma série de outros problemas, tais como: poluição visual (devido à disposição das sacolas nas ruas), interferência na alimentação da vida selvagem, alteração da biodiversidade, entupimento das vias públicas de drenagem e foco no crescimento de larvas de mosquitos transmissores de doenças. (SANTOS, et al., 2012)

Segundo Sobral, Frias e Martins (2011), Os principais problemas das sacolas plásticas não são explicados somente uso abundante ou pela circulação desmedida desse objeto, mas também pelo descarte inconsciente desse material, ou até pela ausência de uma política que conscientizasse as formas de despejo esse tipo de material levará séculos para se decompor.

É importante salientar o impacto que o uso exagerado de plástico causa ao ecossistema marinho. De acordo com Sobral, Frias e Martins (2011), a dispersão e acumulação de plásticos é um problema crescente à escala global, afetando todos os ambientes marinhos, onde pode-se encontrar plástico a flutuar na superfície da água ou depositados na areia. A poluição dos oceanos pelos plásticos é extremamente preocupante devido a seu tempo de decomposição, e por serem vetor em potencial de exposição e transferência de compostos orgânicos de grande toxicidade.

Segundo Araújo e Costa (2006), acúmulos de lixo favorecem o desenvolvimento de microrganismos como fungos, vírus e bactérias, que causam doenças humanas como micoses, 
hepatite e tétano; ou abrigam vetores de doenças, como moscas, baratas e ratos. A poluição no ambiente marinho também afeta diretamente comunidades tradicionais, como os pescadores artesanais. Suas reclamações mais comuns são a presença de plásticos e outros materiais nas redes e linhas de pesca, além de lesões individuais e perda de equipamentos.

O número de pessoas que têm modificado os hábitos em favor da natureza cresceu nos últimos anos. Isso aconteceu através da conscientização da população sobre os problemas ambientais atuais e a preocupação com o futuro tem ganhado cada vez mais força.

Assim, dentre as alternativas para a redução dos problemas relacionados às sacolas plásticas, está a utilização de sacolas reutilizáveis. De acordo com Garcia, Tavares e Carriço (2011), as sacolas retornáveis são confeccionadas com lona ou PVC, elas são antifungos, têm durabilidade, e ainda assumem visuais cada vez mais personalizados. Várias empresas já estão comercializando essa sacola como uma forma alternativa para a armazenagem dos produtos adquiridos. Essa é a opção mais sustentável, uma vez que têm um tempo de vida maior e não existem tantos impactos ambientais durante a sua produção. (SANTOS, et al., 2012)

\section{Conclusões}

É notório que a abordagem dessa temática é de extrema importância, uma vez que os resíduos produzidos poluem o meio ambiente e provocam danos. Dessa forma, passar a reciclar alguns objetos; separar os resíduos de acordo com sua classificação; levar o e-lixo a pontos de coleta; e evitar o uso exagerado de plástico no dia a dia, são de tal modo, fatores essenciais para que se possa harmonizar a relação do homem com o meio ambiente. Entretanto, para que essas ações sejam feitas, é preciso ter o apoio daqueles que farão parte da sociedade no futuro. Portanto, a geração $\mathrm{Z}$ tem o poder de reverter a atual situação e evitando assim, que a natureza tome um curso catastrófico por conta da interferência humana.

\section{Referências}

ABRELPE. Brasil produz mais lixo, mas não avança em coleta seletiva. Disponível em: $<$ http://abrelpe.org.br/brasil-produz-mais-lixo-mas-nao-avanca-em-coleta-seletiva/>. Acesso em: 29 de set. de 2019.

ALENCAR, M. M. M. Reciclagem de lixo numa escola pública do município de Salvador. Revista Virtual Candombá, v. 1, n. 2, p. 96-113, jul-dez. 2005. 
ANTQUEVES, L. M. C.; BOSA, C. R.; DUBIASKI-SILVA, J. A educação ambiental e atividades lúdicas: um incentivo a mudança de hábitos na geração de lixo. Revista Monografias Ambientais, v. 14, n. 2, p. 183-192, mai-ago. 2015.

ARAÚJO, M. C. B.; COSTA, M. F. Lixo no ambiente marinho. Ciência Hoje, vol. 32, n $^{\circ}$ 191, p. $64-69.2003$.

BRASIL. Ministério do Meio Ambiente. Coleta seletiva. Disponível em: $<$ https://www.mma.gov.br/informma/item/7656-reciclagem>. Acesso em: 4 de nov. de 2019.

Ministério do Meio Ambiente. Reciclagem. Disponível em: <https://www.mma.gov.br/informma/item/7656-reciclagem>. Acesso em: 4 de nov. de 2019.

CALVÃO, A.M. et al. O lixo computacional na sociedade contemporânea. In: Encontro Nacional de Informática e Educação, 1, Niterói, RJ. Anais... Niterói, RJ: UFF.

CARDOSO, F. C. I.; CARDOSO, J. C. O problema do lixo e algumas perspectivas para a redução de impactos. Ciência e Cultura, v. 68, n. 4, out-dez. 2016.

COMISSÃO DA CARTA DA TERRA. Carta da Terra. 1992. Disponível em: www.mma.gov.br/estruturas/agenda21/_arquivos/carta_terra.doc. Acesso em: 13 out. 2019.

CELINSKI, T. M. et al. A gestão do lixo eletrônico: Desafios e oportunidades. In: Congresso Brasileiro de Gestão Ambiental, Salvador. Anais... Salvador: IBEAS, 2013.

CELINSKI, T. M. Perspectivas para reuso e reciclagem do lixo eletrônico. In: Congresso Brasileiro de Gestão Ambiental, 2, 2011, Ponta Grossa (PR). Anais... Ponta Grossa: UEPG, 2011.

ORGANIZAÇÃO DAS NAÇÕES UNIDAS - ONU apud INSTITUTO AKATU. Impacto ambiental dos plásticos é de pelo menos US\$ 75 bi ao ano. 2014. Disponível em: $<$ https://www.akatu.org.br/noticia/onu-impacto-ambiental-dos-plasticos-e-de-pelo-menos-us75-bi-ao-ano/>. Acesso em: 6 de nov. de 2019.

FARIA, F. P.; PACHECO, E. B. A. V. A reciclagem de plástico a partir de conceitos de Produção Mais Limpa. GEPROS - Gestão da Produção, Operações e Sistemas, Ano 6, ${ }^{\circ}$ 3, p. $93-107$, jul-set. 2011

FROTA, A. J. A. et al. Implantação de um sistema de coleta seletiva: Aspectos legais e de sustentabilidade. Revista Gestão e Sustentabilidade Ambiental, v. 4, n. 1, p. 129 - 155, abrset. 2015.

GARCIA, K.; TAVARES, M. J.; FERREIRA, R. M. C. Sacolas retornáveis: uma análise semiótica. In: CONGRESSO BRASILEIRO DE CIÊNCIAS DA COMUNICAÇÃO, 34., 2011, Recife. Anais eletrônicos... Recife: Intercom, 2011.

HOCH, P. A. A obsolescência programada e os impactos ambientais causados pelo lixo eletrônico: o consumo sustentável e a educação ambiental como alternativas. In: Seminário 
Nacional Demandas Sociais e Políticas Públicas na sociedade contemporânea, 7, 2016, Santa Cruz do Sul (RS). Anais... Santa Cruz do Sul: UNISC, 2016.

LANDIM, A. P. M. et al. Sustentabilidade quanto às embalagens de alimentos no Brasil. Polímeros: Ciência e Tecnologia, v. 26, p. 82-92, 2016.

LOBO, F. Metais tóxicos e suas consequências para a saúde humana. Disponível em: $<$ https://www.ecodebate.com.br/2011/08/01/metais-toxicos-e-suas-consequencias-para-asaude-humana-artigo-de-frederico-lobo/>. Acesso em: 28 de set. de 2019.

PIATTI, T.M.; RODRIGUES, R. A. F. Plásticos: Características, usos, produção e impactos ambientais. Maceió: EDUFAL, 2005.

SANTOS, A. S. F. et al. Sacolas plásticas: destinações sustentáveis e alternativas de substituição. Polímeros, v. 22, n. 3, p. 228-237, 2012.

SANTOS, F. H. S.; SOUZA, C. E. G. Resíduos de origem eletrônica. Série Tecnologia Ambiental. Rio de Janeiro: CETEM/MCT, 2010.

SOBRAL, P.; FRIAS, J.; MARTINS, J. Microplásticos nos oceanos - um problema sem fim à vista. Revista Ecologia, n. 3, p. 12 - 21, 2011.

SOUZA, J. C. Reciclagem e sustentabilidade ambiental: a importância dos processos logísticos. Transportes, v. 19, n. 1, 2011.

WIESEL, G. Geração Z: sustentáveis, exigentes e seus futuros clientes. Disponível em: $<$ https://www.catho.com.br/carreira-sucesso/carreira/sem-categoria/geracao-z-sustentaveisexigentes-e-seus-futuros-clientes/>. Acesso em: 29 de set. de 2019. 